Proceedings of the Seminar on the Social and Economic Effects

of Earthquake Prediction, 12 October, 1977.

\title{
THE POLICE ROLE
}

\author{
R. S. Mitchell*
}

\section{INTRODUCTION}

The traditional role of the Police in our society is to:

(a) Safeguard life and property;

(b) Preserve the peace;

(c) Prevent crime;

(d) Detect and apprehend offenders against the law.

Police reaction to any emergency situation is based on the requirement to carry out their functions under these general headings in the particular situation that prevails.

\section{DISASTER PLANNING}

Existing contingency plans to cope with disaster, though tailored to meet the particular needs of each community, cannot take into account the precise circumstances which will prevail at the time that an earthquake occurs. When earthquake prediction becomes an accepted scientific reality, the accent in planning will change from preparation for disaster to preparation to avert disaster. Planners will be able to decide upon the best ways to minimise the effect of an earthquake in a given community well in advance of an actual prediction. At the present time the Police participate in planning on a national basis as a member of the National Civil Defence Committee, and at regional and local levels close liaison is maintained between the Police and Civil Defence organisations.

\section{LAW AND ORDER}

In times of crisis the public often turns to familiar authority for help. overseas experience of emergencies has shown that some display of public hysteria can be expected following an earthquake prediction. The Police have an important role to play in maintaining public morale by providing factual information, and at the same time, reassurance and guidance to a concerned and bewildered general public.

When evacuation of a threatened area begins, the Police will be faced with the responsibility for preventing looting of evacuated and partially evacuated areas. At the same time that evacuation begins, people from outside the threatened area can be expected to converge upon it. Some of these people will be anxious to assist friends and relatives, whilst others will be predators intent on taking advantage of the general evacuation. The problem of maintaining security of an evacuated area is a massive one. Constant patrolling to prevent

* National Co-ordinator, Search and Rescue, Police Department. looting would severely tax Police resources, and a decision to reduce Police strength in a threatened area for reasons of human safety would automatically reduce the effectiveness of the Police in controlling crime. Although most people will take heed of the warning to evacuate, it can be expected that some will refuse to budge. This reaction can arise from the tendency of some people in times of crisis to gather their loved ones around them and await their fate, or from sheer disbelief in the validity of the prediction. Either way, the presence of such people in a threatened area will pose problems for the Police and for Civil Defence authorities supervising an evacuation. It is suggested that existing legislation which empowers Police or Civil Defence authorities to order the evacuation of a building or area during a civil defence emergency, was not designed to cope with such a situation, particularly when such people might number several thousand in a densely populated area.

Evacuation of a densely populated area will mean that other places will experience a sudden upsurge in population. Police in such places will be faced with a proportionate upsurge in crime, requiring additional staff for the period of the emergency.

\section{GENERAL}

It is reasonable to expect that an earthquake warning would be promptly followed by the declaration of a state of civil defence emergency. Overall police action would be in accordance with the pre-arranged plan for the threatened area, and in support of the Civil Defence Organisation.

Many of the activities undertaken by the Police will be complicated by the fact that the danger is not readily discernable by the public at large. The necessity to cope with people who do not recognise that an emergency exists will pose particular human problems for the Police. New Zealand has little recent experience of any type of major disaster, and the complacency which is evident in our society today will be a major obstacle to the effective use of earthquake prediction.

\section{CONCLUSION}

From the Police viewpoint, the advent of earthquake prediction is to be welcomed. The advantages of knowing when to expect an earthquake far outweigh any complications which the Police might be required to face in coping with the emergency created by an earthquake prediction.

Universal public acceptance of the 
scientific validity of earthquake prediction will be necessary before the prevention of injury and loss of life that a prediction makes possible can be achieved. Such

public acceptance would greatly simplify the duties of the Police in the wake of a

prediction and in the aftermath of a major earthquake. 